Universidad de Guadalajara

Derecho Global. Estudios sobre Derecho y Justicia

Año 4, núm 11, marzo - junio 2019, pp- 171-177, ISSN: 2448-5128, e-ISSN: 2448-5136

https://doi.org/10.32870/dgedj.v0i11.221

\title{
La sucesión en el pasivo hereditario y la liquidación de la herencia tras la Ley 15/2015 de Jurisdicción Voluntaria
}

\section{Elena Goñi Huarte}

Universidad Europea

La sucesión hereditaria en nuestro Derecho Civil común sigue rigiéndose por los principios tradicionales "antes es pagar que heredar" y "no hay herencia sino residuo". Están relacionados con la necesidad de mantener la garantía patrimonial universal (art. 1911 CC) con la que cuentan los acreedores de la herencia. Para la efectividad de tales principios es necesaria la separación o autonomía del patrimonio hereditario respecto del patrimonio del heredero, que no solo se consigue con la aceptación a beneficio de inventario.

Bajo el título "La autonomía del patrimonio hereditario en la sucesión mortis causa" comienza el primer capítulo de la obra. En él se analiza la necesaria autonomía del patrimonio hereditario que permite hacer efectiva la preferencia al cobro de los acreedores de la sucesión. Así, frente a la concepción personalista de la sucesión del Derecho romano (el heredero es un continuador de la personalidad del difunto), se ha impuesto la tesis de la concepción patrimonialista (el heredero se subroga en la posición del causante), donde no opera la fusión de patrimonios del causante y del heredero. Ahora bien, la separación de patrimonios no se produce de forma automática, de ahí que el ordenamiento conceda una serie de instrumentos destinados a conservar la autonomía del patrimonio hereditario a lo largo del iter sucesorio. De forma que la separación solo se produce ope legis cuando la herencia está yacente, cuando existen varios herederos en situación de comunidad hereditaria y cuando la herencia está en concurso. Pero la separación 
también puede producirse a instancia del heredero (cuando acepta a beneficio de inventario) y a instancia de los acreedores de la sucesión (con el beneficio de separación y a través de la anotación preventiva de créditos y legados).

A continuación se analiza la responsabilidad de los sucesores mortis causa por las deudas hereditarias, que es prácticamente indisponible para el testador y el sucesor. Los sucesores a título particular responden intra vires (con los bienes de la herencia) y los sucesores a título universal responden ultra vires (con los bienes de la herencia y con sus propios bienes), a menos que acepten la herencia a beneficio de inventario. En el capítulo se examina la responsabilidad de los sucesores especiales (heredero en cosa determinada, los legatarios y donatarios de parte alícuota y el llamado a un usufruto), y la responsabilidad del heredero por las deudas de la sucesión. La reforma de la Jurisdicción Voluntaria ha confirmado que la finalidad del beneficio de inventario es limitar la responsabilidad. Ahora bien, si el heredero pierde este beneficio de inventario, responderá también con sus propios bienes, pero sin que se produzca la confusión de su patrimonio con el del causante en perjuicio de los acreedores de la herencia. Éstos seguirán contando con la preferencia al cobro sobre el patrimonio hereditario que se mantendrá separado del patrimonio del heredero. Si el heredero acepta pura y simplemente, los acreedores de la sucesión pueden dirigirse contra el patrimonio hereditario y contra el del heredero, pero solo si pueden mantener el patrimonio hereditario separado podrán cobrar con cargo a él, con preferencia frente a los acreedores del heredero. Esta responsabilidad del heredero se extiende a otros gravámenes de la herencia: la legítima y los legados.

Sin embargo, la responsabilidad del legatario, sucesor a título particular, es distinta. El legatario no responde en principio del pasivo hereditario, salvo que los bienes legados sean necesarios para pagar a los acreedores de la herencia, o que el testador haya gravado el legado con alguna deuda, o que toda la herencia haya sido distribuida en legados. Los donatarios mortis causa y reservatarios, son sucesores a título particular y responden como el legatario. Por último, el capítulo examina la distribución de la responsabilidad cuando son varios los sucesores. Desde la aceptación de la herencia hasta la partición, para proteger a los acreedores que antes tenían un solo deudor, la masa hereditaria permanece 
indivisa, y los coherederos responden de las deudas de forma solidaria. Solidaridad que se recoge en el artículo 1084 CC para cuando está hecha la partición, y que la jurisprudencia y la doctrina mayoritaria entienden aplicable a los coherederos antes de la partición. De forma mayoritaria se entiende que es solidaria la responsabilidad de los colegatarios por las deudas de la herencia, y de forma indiscutible si toda la herencia está distribuida en legados. Distinta de la responsabilidad por las deudas, es la responsabilidad por los legados, que es mancomunada.

En el capítulo tercero se analiza la administración del patrimonio hereditario en el iter sucesorio tras la Ley 15/2015. Con la administración de la herencia se procuran los medios necesarios para evitar la dispersión del patrimonio hereditario, antes y después de la aceptación. Es necesario el nombramiento de un administrador (por el testador, por los herederos, por el notario o judicialmente) con facultades para conservar los bienes de la herencia y realizar las operaciones de liquidación de las deudas y cargas hereditarias. Salvo en el caso de aceptación simple por un único heredero (que permite a los acreedores hereditarios dirigirse contra el patrimonio del heredero), las operaciones de liquidación reguladas en el Código Civil para la herencia aceptada a beneficio de inventario, resultarán de aplicación a la herencia aceptada pura y simplemente por varios herederos. En este caso, la comunidad mantiene la autonomía del patrimonio hereditario, pero antes de proceder a su partición, hay que liquidar las deudas de la herencia. Así, con cargo al patrimonio hereditario deben cobrar en primer lugar, los acreedores de la herencia, después los legitimarios y a continuación los legatarios. Porque la forma de aceptar solo afecta a la responsabilidad de los herederos, pero no a la liquidación de la herencia.

El pago de las deudas debe hacerse con los bienes de la herencia (responsabilidad cum viribus), y solo el remanente quedará a disposición del heredero. Con la partición de la herencia se pone fin a la comunidad hereditaria, transformándose las cuotas en titularidades concretas. Hasta entonces, la indivisión de la herencia no perjudica a los acreedores de la sucesión, porque mantienen separado el patrimonio hereditario, garantía de sus créditos. Tampoco en la partición, porque las deudas no son objeto de partición, pero los acreedores 
de la herencia pueden oponerse a ella, impidiendo a los acreedores del heredero embargar bienes de la herencia. De esta manera se articula el beneficio de separación que permite a los acreedores de la herencia mantener su preferencia frente a los acreedores de heredero.

El capítulo cuarto se dedica al estudio del beneficio de inventario notarial. En garantía de los acreedores hereditarios el Código Civil (art.1003) dispone que en principio la responsabilidad del sucesor es ultra vires, pero le otorga un instrumento potestativo para limitar su responsabilidad intra vires: el beneficio de inventario. Se demuestra así que la separación o autonomía del patrimonio hereditario no se produce automáticamente, como tampoco es automática la limitación de la responsabilidad del heredero. Para ello, son determinantes la voluntad y el comportamiento del heredero. La reforma de la Ley 15/2015 mantiene este sistema pero dota al beneficio de inventario notarial de novedosas condiciones que mejoran su eficacia. El beneficio de inventario se concibe en la actualidad como un procedimiento liquidatorio, más que como un modo de aceptación de la herencia. La condición de heredero se adquiere con la aceptación, sea pura y simple o a beneficio de inventario, pero con éste último, el heredero puede limitar su responsabilidad, dadas las garantías que se ofrecen en la liquidación a todos los interesados en el patrimonio hereditario.

Para que pueda producirse cuanto antes la designación del responsable de las deudas, la Ley de Jurisdicción voluntaria ha reformado la interpellatio a los llamados para que acepten o repudien, pues antes era exclusivamente judicial, y ahora se permite su ejercicio de forma notarial. También ha agravado la sanción del que no contesta a la interpellatio, estableciendo una presunción iuris et de iure de aceptación pura y simple. Pero también permite que el llamado a la herencia ejercite su derecho de deliberar antes de la aceptación de forma notarial. Además, la nueva regulación ya no hace referencia a la aceptación a beneficio de inventario, sino que éste se concibe como un modo de gestionar la herencia que salva al heredero de la responsabilidad ultra vires. Esta «declaración de hacer uso del inventario» es distinta de la aceptación que puede ser anterior, simultánea o posterior al inventario. La nueva regulación unifica el plazo en treinta días para utilizar el beneficio de inventario, y permite ahora citar a los 
acreedores conocidos y a los desconocidos por edictos. Tras la descripción de la formación del inventario, se señala la necesidad de realizar el inventario en plazo, ya que el retraso culposo o negligente supone la pérdida del beneficio tal y como ocurre con la ocultación o sustracción de bienes. Con la pérdida del beneficio, la responsabilidad del heredero pasará a ser ultra vires y se producirá la confusión del patrimonio hereditario con el patrimonio del heredero. Pero esta confusión no se producirá en perjuicio de los acreedores hereditarios que mantendrán su preferencia al cobro. Para ello, como la autonomía del patrimonio hereditario no es automática, los acreedores deberán ejercitar el beneficio de separación, que se estudia en el capítulo siguiente.

Aunque el Código Civil no lo contemple expresamente, sí contiene diversos instrumentos que permiten reconocer un beneficio de separación a los acreedores hereditarios para impedir la confusión del patrimonio de su deudor con el del sucesor, pudiendo así verse postergados. Ello demuestra que la separación de patrimonios de causante y del heredero no es automática. Con fundamento en el principio "primero es pagar que heredar", el Derecho Civil común otorga preferencia a los acreedores del causante sobre los legatarios y los acreedores del heredero, así como preferencia a los legatarios respecto de estos últimos. Para llevar a cabo las preferencias de cobro, es necesario mantener separado el patrimonio hereditario. Con el beneficio de inventario se consigue esta separación, pero queda en manos del heredero. Por eso, el beneficio de separación no declarado se otorga también a los acreedores hereditarios: con la intervención y la oposición a la partición, así como con la anotación preventiva de derechos. También se contempla la anotación preventiva de los legados. Con la Ley de Jurisdicción Voluntaria, que ha ampliado las competencias del notario en la partición para restringir la intervención judicial a lo imprescindible, consideran las autoras que se introduce un beneficio de separación notarial. Porque los acreedores podrán formular la oposición ante notario, antes y después de aprobada la partición, para suspender la entrega hasta que los créditos sean pagados o garantizados. Por último, se analizan otros instrumentos subsidiarios de los acreedores para el cobro: la acción de los acreedores del causante frente a los legatarios, la acción pauliana y la posibilidad de instar la ineficacia de la partición. 
Para completar el estudio de la sucesión del pasivo hereditario y la liquidación de la herencia, el último capítulo se dedica a analizar la posición de los acreedores del heredero que pueden verse perjudicados por la sucesión. Así, se analizan los medios de los que disponen para salvaguardar sus créditos a lo largo del iter sucesorio: el embargo del derecho hereditario; las facultades de los acreedores particulares del llamado a una herencia, referidas al ejercicio de su ius delationis, la interrogatio o interpellatio al llamado a la herencia que no la acepta ni la repudia; la aceptación de la herencia por los acreedores particulares del llamado que repudia; la aceptación del heredero en perjuicio de sus acreedores; y la situación particular de los acreedores del concursado llamado a una herencia y del llamado a una herencia que se declara en concurso. También se estudian las posibilidades de los acreedores del heredero en el iter sucesorio una vez aceptada la herencia: la facultad de personarse en la formación del inventario que se realiza con la intervención de la herencia y el derecho a intervenir en la partición. Finalmente, se examina el beneficio de separación instado por los acreedores del heredero (regulado en el Libro Cuarto del Código Civil de Cataluña); y los instrumentos para la protección de los acreedores del heredero en Derecho común (la acción pauliana para impugnar la aceptación realizada en fraude a su derecho y la posibilidad de instar el concurso del heredero).

La obra comentada resulta de gran utilidad porque aborda los problemas que pueden plantearse con la sucesión de las deudas hereditarias y la garantía patrimonial universal de los acreedores del causante. El estudio del tema se realiza de forma profunda, analizando e interpretando antiguas discusiones doctrinales y jurisprudenciales, con una visión pragmática de las mismas. Además, se valoran y cuestionan las modificaciones introducidas por la Ley 15/2015 que afectan a las sucesión del pasivo hereditario y a su liquidación, y se aportan propuestas de reforma. Todo ello permite al lector tener una visión completa de la materia y comprender los mecanismos de actuación en la resolución de los conflictos que puedan plantearse en la sucesión del pasivo hereditario y la liquidación de la herencia. 


\section{Bibliografía}

Libro: La sucesión en el pasivo hereditario y la liquidación de la herencia tras la Ley 15/2015 de Jurisdicción Voluntaria

Autores: María Belén Sáinz-Cantero Caparrós y María Angustias Martos Calabrus Editorial: Editorial Comares

Lugar: España

Año: 2017 
